on sucrose, of course, but much more on the history of nutrition, notably the succinct biographies of many of the founders of nutritional science and the accounts of the food habits and nutritional impact of the Neolithic revolution. The air of relaxed authority emerges in entries such as that on "Food", which he calls "a word universally used and presumably universally understood" but not susceptible of a "sufficient and necessary definition" before going on gently to refute the slick definitions found in dictionaries. This a reference work to browse through and ruminate upon. It will be particularly useful to those who feel impelled to pronounce upon nutritional matters, among whom one might include the authors of the third book reviewed here.

Diet-Related Diseases, a ollaborative effort by an epidemiologist, an immunologist, a chemist and a clinical psychologist, is a refreshing book but suffers from three things. The first is the unevenness in style, predictable in a multiple-author volume. The second is the cover: a clichéd photograph of a collection of junk foods that fails to reflect the thrust of the book and suggests that the publishers did not fully appreciate what their authors have tried to do. For in no sense is this book clichéd, nor is it particularly concerned to attack or defend junk food. What the authors do is set out what they see as possible roles for diet in many of the diseases of the affluent society, and to present both conventional and novel (and in parts highly idiosyncratic) analyses of this case. The core is a collection of chapters by Stephen Seely which set out the evidence for a dietary role in arterial diseases and various cancers; on the periphery are chapters by his colleagues on food toxicants, food allergies, diet in mental illness, and diet and ageing.

Seely is the author of a provocative series of papers in Medical Hypotheses which have tried to cast new light on the welltrodden field of diet and degenerative diseases chiefly by attempting a more thorough analysis of data on national diets and the prevalence data on diseases. While the evidence is set down in the book with commendable clarity, it is the very clarity which makes apparent the occasional, but important, misconception about the quality of the nutritional, and other, assumptions which underpin the arguments.

Here lies the book's third and most serious fault. For example, Seely's analyses make great use of estimates of per capita availability of foodstuffs in various countries, which he calls "food consumption data". They are not: the two may differ by some hundreds of calories and the discrepancy is a notorious source of error. He asserts axiomatically that "a correlation coefficient of 0.9 denotes a degree of positive correlation when causal connection is probable"'. He suggests that the longevity of the human species is explained by our low level of energy consumption for our size. This is an arguable contention, but it

is presented in a way that suggests Seely is unaware of Rubner's work of a century ago which showed that human beings live four times longer than a comparative study of energy turnover would suggest, or of Flourens's (1856) "law of longevity" that lifespan of different species is about five times as long as the duration of the growth period, a generalization that does fit the human species.

Such errors might yield to a more thorough training in nutrition and a respect for its historical background such as is to be found in Yudkin's Encyclopaedia. But though Seely's theories would be better for greater nutritional sophistication, this failing does not destroy the book. What

\section{Biology at work}

\section{Norman Carey}

Biotechnology and Genetic Engineering

Reviews, Vols 1 and 2.

Executive editor Gordon E. Russell.

Intercept, PO Box 2, Ponteland,

Newcastle upon Tyne/Scholium, 265

Great Neck Road, Great Neck,

New York: 1983/1984. Each volume

pp. 450, £50, $\$ 79.50$

AT THE moment that these volumes arrived on my desk for review I was in conversation with one of my colleagues. " $\mathrm{Oh}$ no", he said, "not another one. There's too much being written about biotechnology these days." I suppose the comment could mean either that the topics have already been well covered elsewhere or that the speaker does not have time to read all that appears on the subject. Whether this series really is "too much" depends on the objectives and whether they are achieved.

The term "biotechnology" was coined at the time of the revolution in thinking which was brought about by the arrival of recombinant DNA techniques. To many people it has come to mean the industrial application of recombinant DNA. Indeed, it does to some of the authors of articles in these volumes, as is evidenced by the use of the word (Vol. 1, p.231). Of course, although a new (or at least newly publicized) term, by any definition biotechnology covers a multitude of highly profitable industrial activities which long pre-date the recombinant revolution.

In his preface, the editor refers to this fact. He says that the articles are intended to cover biotechnology "in the widest sense of that word". He implies, however, as does the title of the books, that it is the application of recombinant DNA which is the unifying feature of the articles. If that were the intention, then I feel there would be some value in a series such as this. One is forced to conclude, however, that this cannot be the aim, since many of the contributions scarcely mention in vitro recombination. The first article in Vol. 1, for exam○)1985 Nature Publishing Group particularly recommends itself is not the correctness or otherwise of the authors' specific views, it is an overall air of caution, reasonableness and balance in their tone. Even when the writers are expounding their own pet theories they sound more like judges than prosecutors. I hope they produce more books, because dispassionate commentators will be in demand as nutrition increasingly becomes a public health issue which is seen to require missionary zeal on all sides.

John Rivers is a Senior Lecturer in the Department of Human Nutrition at the London School of Hygiene and Tropical Medicine, University of London.

ple, "Applications of Biocatalysts to Biotechnology" (a few years ago this would have been called "Industrial Applications of Enzymes"), mentions genetics and protein engineering once, in the penultimate paragraph of the conclusions.

Perhaps, then, I have read too much into the title and preface. Maybe the series is intended to be a set of reviews on biotechnology and the title just has a high buzz-word quotient. In that case, the volumes should be judged by the quality of the articles and need for a review of each field. While there are a number of similar review series without a recombinant slant, this kind of duplication has not been a disadvantage in any other field.

Most of the contributions are informative and well written. However, there is an unnecessary degree of superficiality and repetition which a firm editorial hand should have dealt with. For example, three of the articles in Vol. 2 contain accounts of how to do cDNA and genomic cloning which are at once too slight to be of value to anyone who wishes to learn the techniques and too familiar to anyone with a degree in biochemistry. Such descriptions are now in the textbooks and do not belong in a series of "up to the minute in-depth reviews", to quote the preface again.

Librarians in industrial laboratories may subscribe to this series. But I think it likely that they will consider that scientists in their companies already know more about the topics in their own fields than these articles contain, and that they would have no reason to refer to such a wide variety of other subjects. However, libraries serving university departments of biochemistry and microbiology should have it. As general reading, most of the articles would be valuable to advanced and even first degree students; moreover, they do provide an excellent picture of the breadth of application of their disciplines. This series shows biotechnology both as high-quality science and as an important and valuable industrial activity. 